\title{
PENDEKATAN METODE ALTMAN Z-SCORE DALAM PENENTUAN INSENTIF BONUS PEGAWAI
}

\author{
Dine Tiara Kusuma"); M. Yoga Distra Sudirman ${ }^{2)}$; Yessy Fitriani ${ }^{3)}$ \\ Jurusan Teknik Informatika, Sekolah Tinggi Teknik PLN \\ Email: dinetiara@sttpln.ac.id
}

\begin{abstract}
Human resource management is one area of management that specifically studies the relationships and the role of humans in the organization. Human resource management can also produce a good performance in a company by way of valuation, reward service in each individual member organization in accordance with its work ability. Revenue earned by each individual will be different, including bonuses or incentives that are very useful to improve work motivation. Incentives given to each employee certainly not the same from one to another. This incentive calculation process requires the index as a factor factor in its final outcome. One method that can be used in the determination of the index is by using the Altman Z-Score method. This method can be used for determining the value used for the determination of bonus incentives.
\end{abstract}

Keywords: Incentives, Altman Z-Score, Scoring Index

\begin{abstract}
Abstrak
Manajemen sumber daya manusia merupakan satu bidang manajemen yang khusus mempelajari hubungan dan peranan manusia dalam organisasi. Manajemen sumber daya manusia juga dapat menghasilkan kinerja yang $b$ aik dalam sebuah perusahaan dengan cara penilaian, pemberian balas jasa dalam setiap individu anggota organisasi sesuai dengan kemampuan kerjanya. Pendapatan yang diterima oleh setiap masingmasing individu akan berbeda termasuk bonus ataupun insentif yang sangat berguna untuk meningkatkan motivasi kerja. Insentif yang diberikan kepada setiap karyawan tentunya tidak sama antara satu dengan yang lainnya. Proses perhitungan insentif ini memerlukan index sebagai faktor kali dalam hasil akhir nya. Salah satu metode yang dapat digunakan dalam penentuan index yaitu dengan menggunakan metode Altman ZScore. Metode ini dapat digunkan untuk penentuan nilai yang digunakan untuk penentuan insentif bonus.
\end{abstract}

Kata Kunci: Insentif, Altman Z-Score, Scoring Index

\section{Pendahuluan}

Setiap anggota dari suatu organisasi mempunyai kepentingan dan tujuan sendiri ketika ia bergabung pada organisasi tersebut. Bagi sebagian karyawan, harapan untuk mendapatkan uang adalah satu-satunya alasan untuk bekerja, namun yang lain berpendapat bahwa uang hanyalah salah satu dari banyak kebutuhan yang terpenuhi melalui kerja. Untuk menjamin tercapainya keselarasan tujuan, pimpinan organisasi bisa memberikan perhatian dengan memberikan kompensasi, karena kompensasi merupakan bagian dari hubungan timbal balik antara organisasi dengan sumber daya manusia. Kompensasi yang diberikan terhadap karyawannya ini dapat berupa insentif.

Menurut Malayu S.P Hasibuan (2001:117), mengemukakan bahwa: "Insentif adalah tambahan balas jasa yang diberikan kepada karyawan tertentu yang prestasinya di atas prestasi standar. Insentif ini merupakan alat yang dipergunakan pendukung prinsip adil dalam pemberian kompensasi".

Dalam pemberian insentif kepada karywan dalam suatu perusahaan membutuhkan perhitungan khusus sehingga dapat menghasilkan proses kalkulasi yang maksimal. Proses kalkulasi tentunya harus memperhatikan kriteria-kriteria yang mempengaruhi dalam pemberian insentif tersebut. Penggunaan kriteria-kriteria tertentu dalam pemberian insentif karyawan tentunya membutuhkan suatu metode khusus.

Bedasarkan hal tersebut diatas maka pada penelitian ini di usulkan menggunakan metode tertentu dalam perhitungan index dalam pemberian insentif pegawai, agar index yang dipergunakan dapat bersifat dinamis sesuai dengan kondisi karyawan saat itu. Ada beberapa metode yang digunakan dalam perhitungan index seperti Latent semantic indexing (LSI), Metode Multifactor Evaluation Process (MFEP), Altman Z-Score, dan lain sebagainya. Setelah beberapa review jurnal yang telah dilakukan maka beberapa variable yang dianggap sesuai dengan penelitian ini adalah dengan Altman Z Score. Altman Z-Score adalah skor standard berupa jarak skor seseorang dari mean kelompoknya dalam satuan Standard Deviasi. Kegunaan $Z$ score Membandingkan posisi seseorang dengan orang lain dalam kelompok masing-masing. Altman Z-Score adalah satu teknik statistik yang menghasilkan suatu indeks dimana nantinya memungkinkan pengklasifikasian dari suatu pengamatan menjadi satu dari beberapa pengelompokan yang bersifat apriori. Sehingga akan menghasilkan rumusan dalam suatu rumus matematis.

Hasil penelitian ini diharapkan dapat membantu instansi tersebut dalam pemberian 
kompensasi kepada karywannya sehingga dapat menghindari kesalahan pada pemberian insentif kerja, Penelitian ini akan membahas sebuah sistem dengan judul Pendekatan Metode Altman Z-Score Dalam Penentuan Insentif Bonus Pegawai.

\section{Metodologi Penelitian}

2.1 Langkah-langkah Penelitian

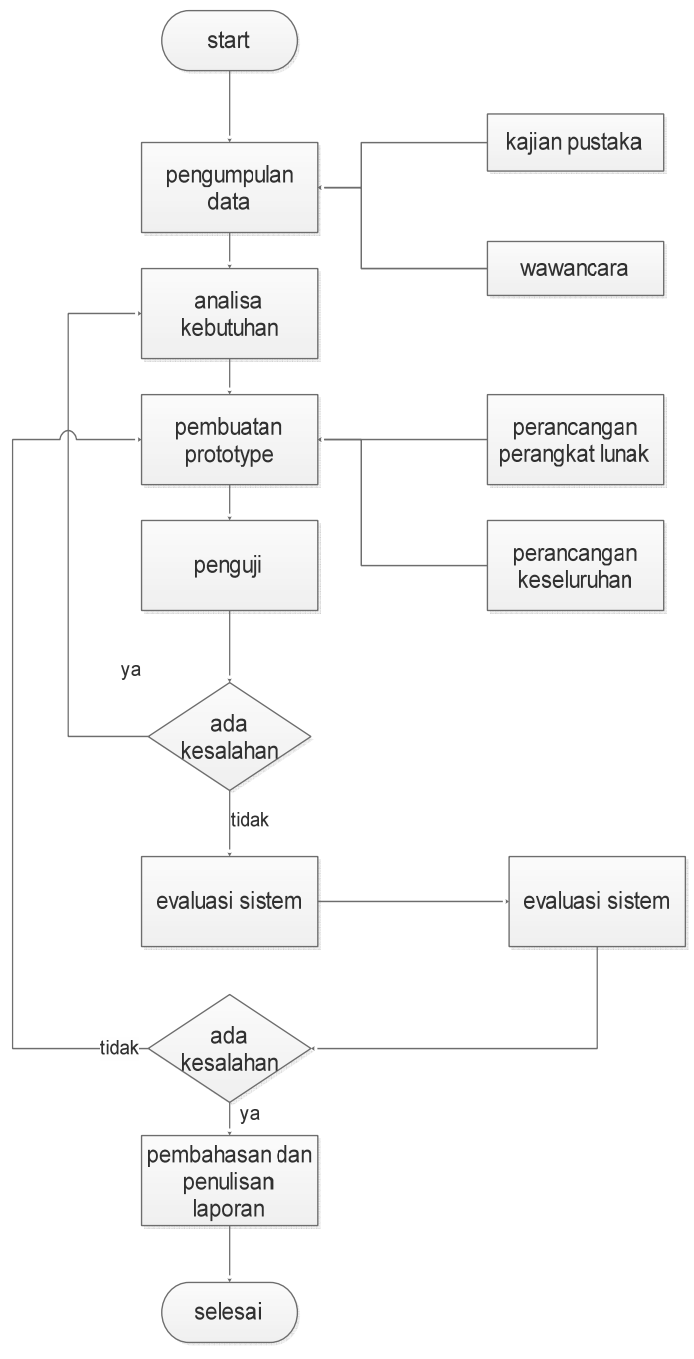

Gambar 1. Bagan Metodologi

a. Pengumpulan data

Pada tahap ini dilakukan analisa terhadap kebutuhan serta kekurangan sistem yang sedang berjalan tersebut agar dapat diketahui poin - poin yang di butuhkan dalam pembuatan sistem sehingga mendapat rancangan aplikasi yang sesuai dengan kebutuhan, yaitu review jurnal serta wawancara dengan pihak yang bersangkutan.

b. Analisa kebutuhan

Pada tahap ini dilakukan analisa kebutuhan kebutuhan dalam membangun aplikasi dan menentukan spesifikasi perangkat keras maupun perangkat lunak yang di butuhkan.

c. Pembuatan prototype

Pada tahap ini dilakukan pembuatan terhadap prototype sistem yang di bangun, khususnya proses coding menggunakan pemrograman
PHP serta perancangan struktur table database dengan menggunaka My SQL dalam perancangan perangkat lunak, serta melakukan perancangan keseluruhan dimana menggabungkan antara source code dengan peancangan tampilan sistem.

d. Pengujian

Pada tahap ini dilakukan pengujian terhadap sistem sesuai dengan yang di inginkan.

e. Ada kesalahan

Pada tahap ini dilakukan pengujian agar tidak terjadi kesalahan maka akan lanjut ke proses selanjutnya tetapi jika dalam proses tersebut terdapat suatu kesalahan maka proses akan kembali lagi ke tahap analisa kebutuhan.

f. Evaluasi sistem

Pada tahap ini evaluasi dilakukan dengan melihat hasil kuisioner apakah sudah sesuai dengan kebutuhan yang di inginkan.

g. Pembahasan dan penulisan laporan

Pada tahap ini dilakukan pembuatan laporan sistem yang telah berjalan sesuai dengan kebutuhan.

\section{Hasil dan Analisa}

\subsection{Form Login}

Tampilan awal dari sistem aplikasi ini adalah menu login, proses login dapat dilakukan oleh admin yang terdaftar dalam aplikasi ini. Proses login dilakukan dengan memasukkan user name dan password. Saat proses login jika proses login gagal maka akan kembali ke form login dan menginputkan username dan password yang benar.

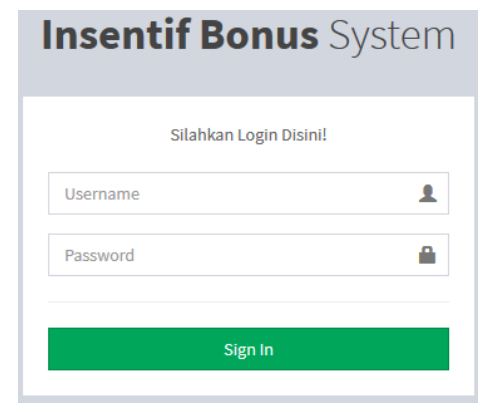

Gambar 2 Tampilan Halaman Login

\section{Halaman Utama}

Halaman Utama yaitu Halaman Awal pada saat admin berhasil melkukan login, tampilan pada system yaitu berisi jumlah Data Pegawai yang terdaftar di dalam system penentuan insentif bonus pegawai.

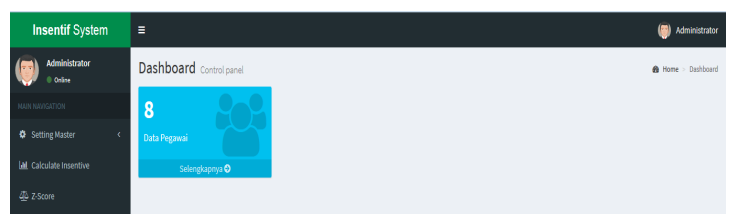

Gambar 3 Tampilan Halaman Utama 


\section{Halaman Data Kualifikasi}

Halaman Data Kualifikasi adalah halaman yang menampilkan kriteria kualifikasi lengkap dengn index dan rating penilaian disini kita juga dapat mengedit nama kulaifikasi, rating dan index yang ada.

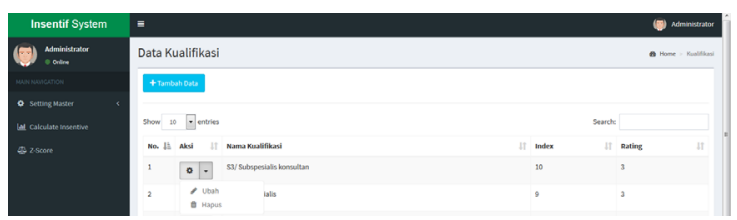

Gambar 4 Tampilan Halaman Data Kulalifikasi

\section{Halaman Tambah Data Kualifikasi}

Halaman Tambah Data Kualifikasi adalah halaman yang digunakan untuk menambah data kualifikasi. Disini data yang di inputkan adalah nama kualifikasi, rating dan index.

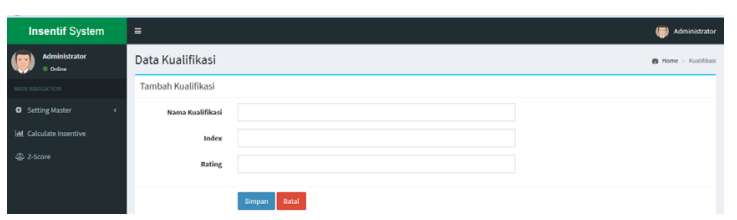

Gambar 5 Tampilan Halaman Tambah Data Kualifikasi

\section{Halaman Data Risk}

Halaman Data risk adalah halaman yang menampilkan kriteria kualifikasi lengkap dengn index dan rating penilaian disini kita juga dapat mengedit nama risk, rating dan index yang ada.

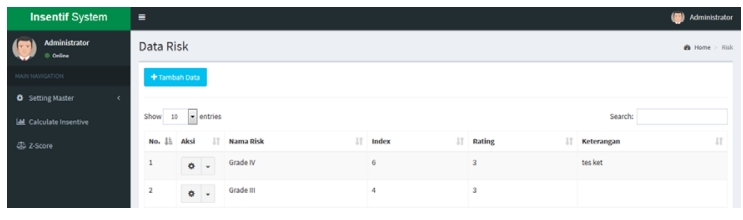

Gambar 6 Tampilan Halaman Data Risk

\section{Halaman Tambah Data Risk}

Halaman Tambah Data risk adalah halaman yang digunakan untuk menambah data kualifikasi. Disini data yang di inputkan adalah nama risk, rating dan index.

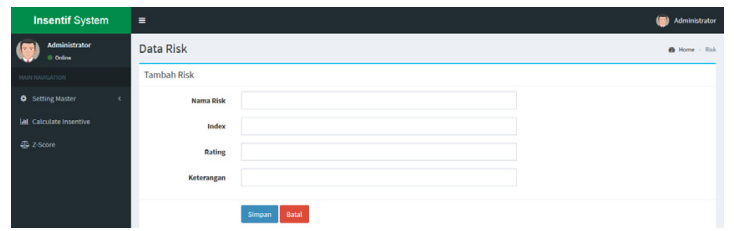

Gambar 7 Tambilan Halaman Tambah Data Risk

\section{Halaman Data Emergancy}

Halaman Data Emergancy adalah halaman yang menampilkan kriteria kualifikasi lengkap dengan index dan rating penilaian disini kita juga dapat mengedit nama emergancy, rating dan index yang ada.

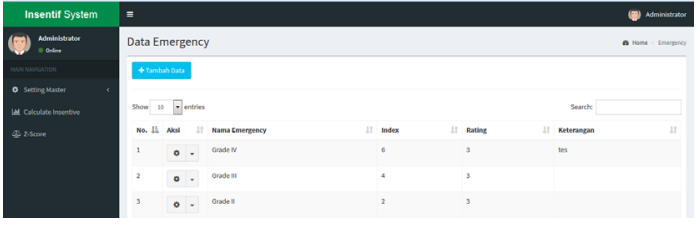

Gambar 8 Tampilan Halaman Data Emergancy

\section{Halaman Tambah Data Emergancy}

Halaman Tambah Data Emergancy adalah halaman yang digunakan untuk menambah data kualifikasi. Disini data yang di inputkan adalah nama emergancy, rating dan index.

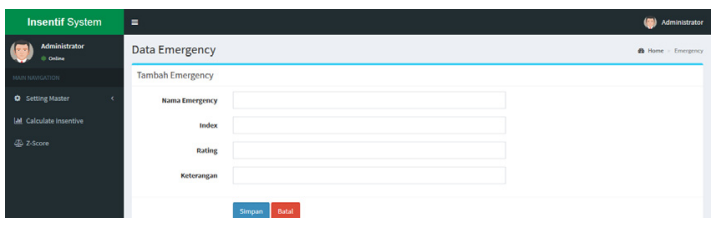

Gambar 9 Tampilan Halaman Tambah Data Emergancy

\section{Halaman Data Position}

Halaman Data Position adalah halaman yang menampilkan kriteria kualifikasi lengkap dengan index dan rating penilaian disini kita juga dapat mengedit nama position, rating dan index yang ada.

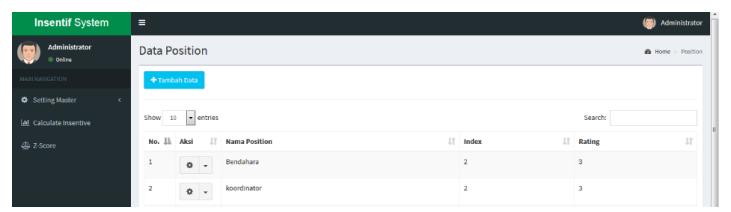

Gambar 10 Tampilan Halaman Data Position

\section{Halaman Tambah Data Position}

Halaman Tambah Data Position adalah halaman yang digunakan untuk menambah data kualifikasi. Disini data yang di inputkan adalah nama position, rating dan index.

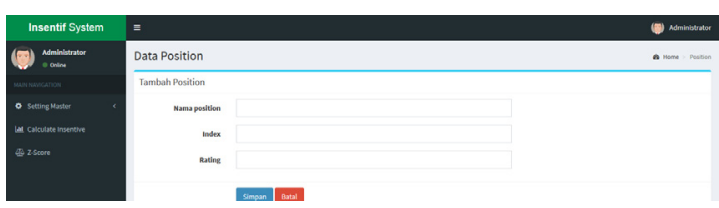

Gambar 11 Tampilan halaman Data Position

\section{Halaman Data Gaji}

Halaman Data Gaji adalah halaman yang menampilkan kriteria gaji dengan masa kerja dalam hal ini untuk halaman gaji - gaji tersebut akan dijadikan index.

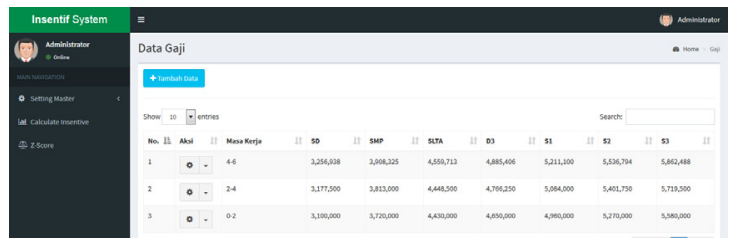

Gambar 12 Tampilan Halaman Data Gaji 


\section{Halaman Tambah Data Gaji}

Halaman Tambah Data Gaji adalah halaman yang digunakan untuk menambah data gaji. Disini data yang di inputkan adalah masa kerja dengan gaji sesuai dengan kualifikasi dari nominal untuk gaji sesuai dengan pendidikan.

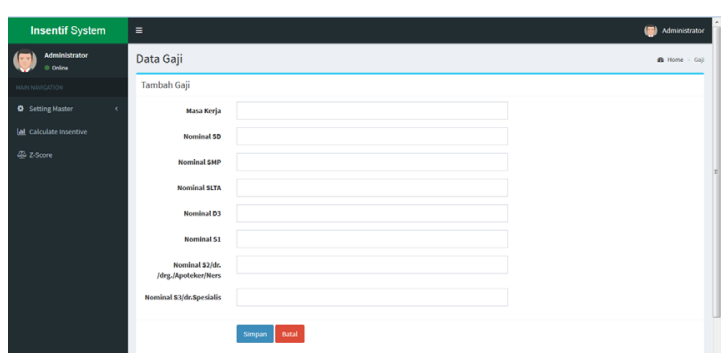

Gambar 13 Tampilan Halaman Data Gaji

\section{Halaman Data Pegawai}

Halaman Data Pegawai adalah halaman yang digunakan untuk menambah data pegawai ataupun edit dan hapus data. Disini admin dapat melihat tampilan dari data pegawai.

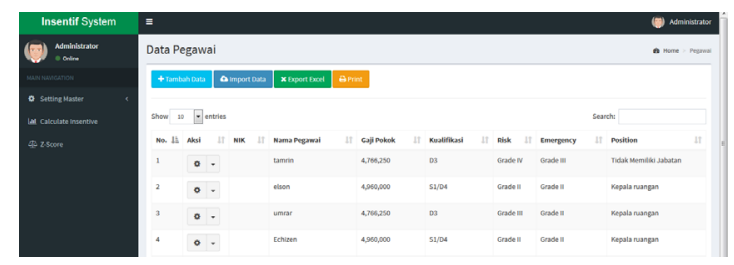

Gambar 14 Tampilan Halaman Data Pegawai

\section{Halaman Tambah Data Pegawai}

Halaman Tambah Data Pegawai adalah pada halaman ini admin dapat meng input data pegawai baru untuk dimasukkan ke dalam database.

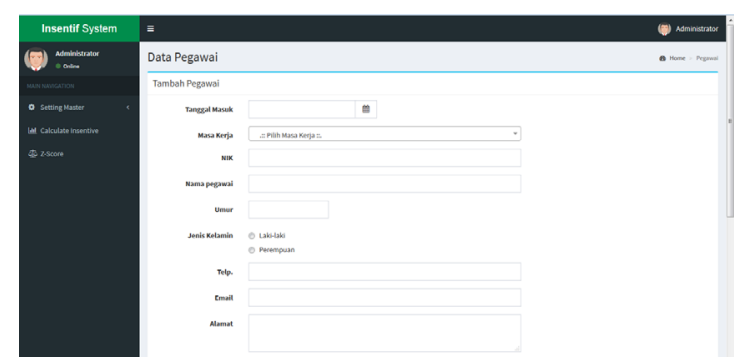

Gambar 15 Tampilan Halaman Tambah Data pegawai

\section{Halaman Import Data Pegawai}

Halaman Import Data Pegawai adalah halaman untuk memasukkan data pegawai baru dengan cara upload file yang akan di pilih dari data yang ada dan disimpan ke dalam database.

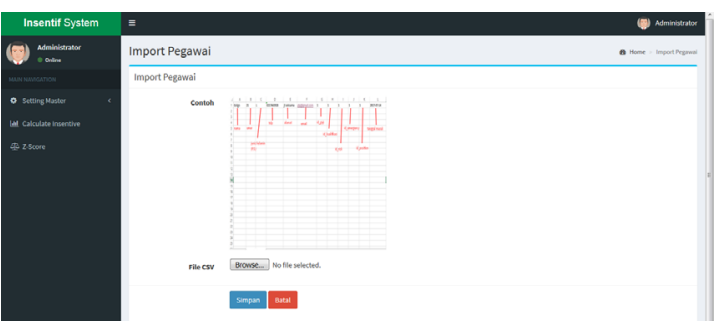

Gambar 16 Tampilan Halaman Import Pegawai

\section{Halaman Export Data Pegawai}

Halaman Export Data Pegawai adalan dimana admin dapat mendownload data excel dari data pegawai.

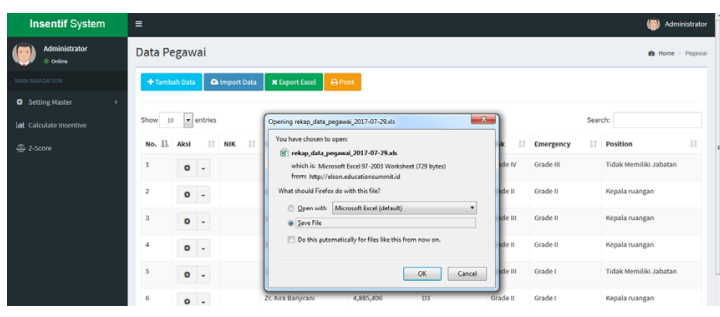

Gambar 17 Tampilan Halaman Export Data Pegawai

\section{Halaman Print Data Pegawai}

Halaman Print Data Pegawai adalah Halaman Untuk Print Data Pegawai dengan semua Data Pegawai.

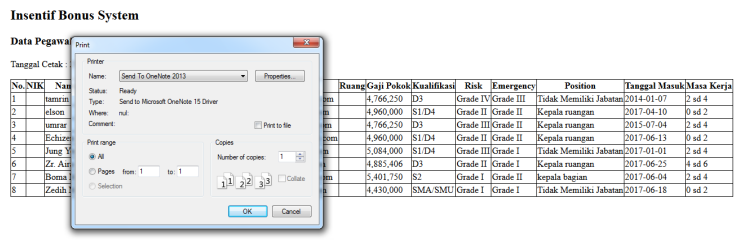

Gambar 18 Tampilan Halaman Print Data Pegawai

\section{Halaman Calculate Insentive}

Halaman Calculate Insentive adalah halaman perhitungan dengan hasil index dan perhitungan dengan mendapatkan insentive yang sesuai dengan data nilai personal yang didapat karyawan.

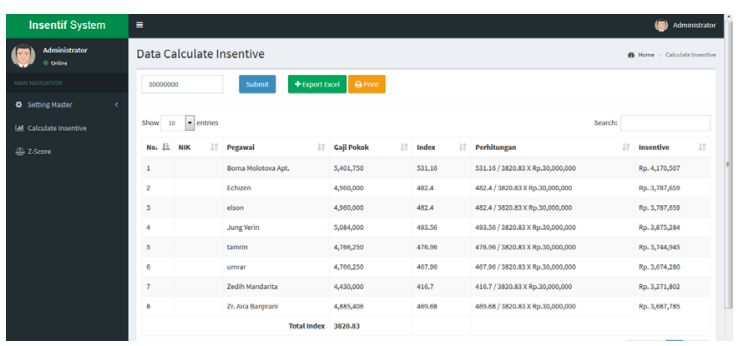

Gambar 19 Tampilan Halaman Calculate Insentive

Halaman Export Data Hasil Calculate Insentive

Pada Tombol Export Data Hasil Calculate Insentive adalah dimana admin dapat export file excel sehingga dapat disimpan rekap dari data calculate tersebut. 


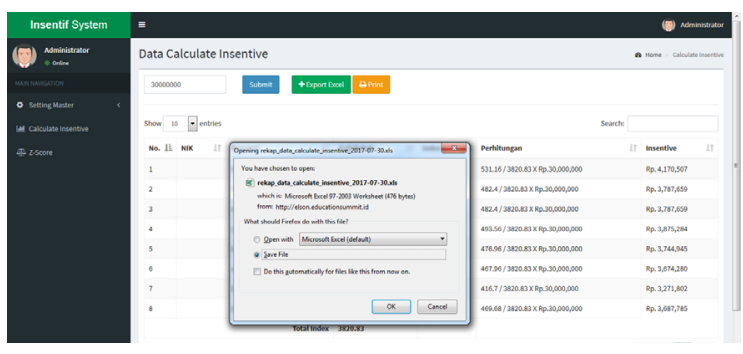

Gambar 20 Tampilan Halaman Export Data Hasil Calculate Insentive

Halaman Print Data Hasil Calculate

Pada Halaman Print Data Hasil Calculate Insentive adalah dimana admin dapat print file data hasil insentive sehingga dapat langsung di cetak.

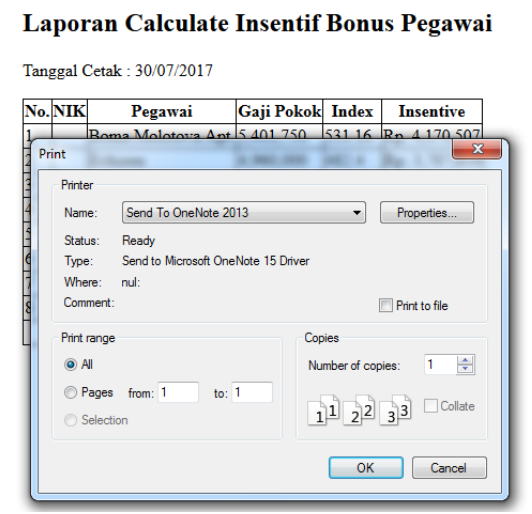

Gambar 21 Tampilan Halaman Print Data Hasil Calculate

\section{Halaman Data Z-Scoring}

Halaman Data Z-Scoring adalah halaman perhitungan hasil scoring index dan digabungkan dengan metode scoring index maka didapatkan hasil index sebagai bahan nilai untuk karyawan dan dijadikan untuk dimasukkan ke dalam Calculate Insentive.

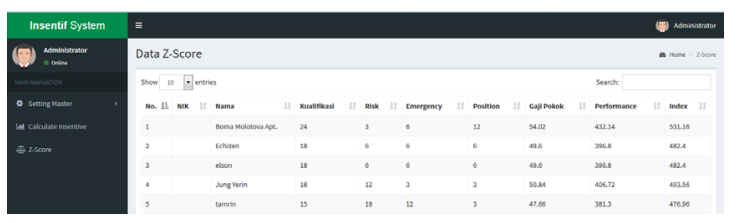

Gambar 22 Tampilan Halaman Data Z-Score

\section{Pembahasan}

Original Z-score (for public manufacturer) Fungsi diskriminan ini dikembangkan untuk perusahaan manufaktur publik.

$Z=0.012 X 1+0.014 X 2+0.033 \times 3+$

$0.006 \times 4+0.999 \times 5$

Dimana:

X1: Modal Kerja / Jumlah Aktiva

X2: Retained Earning / Total Assets

X3: Laba Sebelum Bunga dan Pajak /

Jumlah Aktiva

X4: Nilai Pasar Ekuitas / Nilai Buku Total

Utang

X5: Penjualan / Total Aktiva

Z: Indeks keseluruhan
Dalam hal ini untuk pendekatan metode zscore dalam pengimplementasian ke sistem adalah:

$Z=a \times 1+b \times 2+c \times 3+d \times 4+e x 5+f \times 6$

Dimana:

$a=$ Rating kualifikasi

$b=$ Rating kualifikasi

$\mathrm{c}=$ Rating Risk

$\mathrm{d}=$ Rating Emergancy

$\mathrm{e}=$ Rating Position $\mathrm{i}$

$\mathrm{f}=$ Rating Gaji Pokok

$\mathrm{g}=$ Rating Performa

Sedangkan:

X1 = kualifikasi index

$\mathrm{X} 2$ = Risk index

$\mathrm{X} 3=$ Emergancy index

$X 4=$ Position index

$X 5=$ Basic index

$\mathrm{X} 6=$ Performa index

Contoh Pembahasan penerapan metode altman z-score

Data pegawai yang akan di berikan insentif sesuai dengan hasil perhitungan scoring index yang akan didapatkan dan dikalikan dengan hasil insentif yang akan di terima uleh karyawan tersebut.

1. Nama pegawai: EKO HEPPY PURWANTO, SKM, MM, MARS

2. Tanggal masuk: 2017-06-17

3. Masa kerja: 0 - 2 tahun

4. Status jabatan: Kepala Bagian Umum

5. Pendidikan: S2 Magister Administrasi Rumah Sakit / MARS

6. Unit kerja: bagian umum

7. Maka akan dilakukan perhitungan sebagai berikut:

Dengan hasil masa kerja dan capaian pendidikan maka pegawai yang bernama EKO HEPPY PURWANTO, SKM, MM, MARS mendapah gaji pokok berjumlah: $\operatorname{Rp} 2,560,600$.

\section{Kesimpulan dan Saran}

Altman Z-Score dapat digunakan sebagai salah satu metode dalam mencaro indexdalam menentukan faktor kali terhadap hasil insentive pegawai sehingga dapat di gunakan dalam proses hitung kriteria dari scoring index personal.

\section{Daftar Pustaka}

A. S., Rosa dan Shalahuddin, M. 2013. Rekayasa Perangkat Lunak Terstruktur

Dan Berorientasi Objek. Informatika.Bandung.

Arief, M.R. (2011). Pemrograman Web Dinamis Menggunakan Php dan Mysql. Yogyakarta: ANDI.

Anhar. 2010. PHP \& MySql Secara Otodidak. Jakarta: PT TransMedia

Beta, Ir \& Husni I. Pohan, Ir. M.Eng. 2001. Pemrograman Web dengan HTML.Bandung: Informatika

Utami, Hamid dan Rahmanda. Pengaruh Insentif Terhadap Motivasi Dan Kinerja Karyawan. Malang: Fakultas IImu Administrasi Universitas Brawijaya. 
Pressman, R.S. (2010). Software Engineering: a practitioner's approach (7th ed.). New York: McGraw-Hill.

Perry, CIMA Learning System 2007 Organisational Managementand Information Systems Elsevier Science \& Technology Books, 2006

Sopiyah AriniTriyonowati, 2013, analisis altman zscore untuk memprediksi kebangkrutan padaperusahaan farmasi di indonesia

Sugiarti, Y. (2012). Analisis dan Perancangan UML (Unified Modeling Language) Generated VB.6. Jakarta: Graha IImu.

Wasisto, Edi. 2014. Pengaruh insentif terhadap motivasi kerja dan kinerja pegawai stie adi unggul bhirawasurakarta. Jurnal ADVANCE Edisi Pebruari 2014

W. Tambunan, R., Dwiatmanto, \& N.P, M. W. (2015). Analisis Prediksi Kebangkrutan Perusahaan Dengan Menggunakan Metode Altman (Z-Score). Jurnal Administrasi Bisnis, Volume 2 No. 1 